\title{
An Innovative Technique to Reduce the Lateral Displacement of Building Structures Using Springs
}

\author{
Michel Farid Khouri ${ }^{1}$, Elias Bechara El-Haber ${ }^{2}$ \\ ${ }^{I}$ Department of Civil Engineering, Branch II, Lebanese University, Lebanon \\ ${ }^{2}$ Research Engineer at Lebanese University, Faculty of Engineering, Branch II, Lebanon
}

\begin{abstract}
Limiting lateral displacement is a very important factor in the design and construction of high-rise buildings. This movement is limited by stresses induced in the structure and by the comfort of inhabitants at upper floors. Traditionally, structural bracing through the addition of shear walls and other lateral load resisting elements, in addition to many other methods such as Tuned Mass Dampers (TMD), have been used to reduce lateral displacements. Based on the elastic characteristics of an oscillating spring, this work evaluates the use of high stiffness springs implanted at various locations in a structure and analyzed to check their influence on lateral displacement reduction. Results show that placing a set of springs all around the columns of the upper floor and the floors located at the inflection points of the first three modes can reduce the overall displacement by about $60 \%$.
\end{abstract}

Keywords: Structural Oscillations, Displacement Reduction, Tuned Mass Damper, Mode Shapes, Spring Stiffness, Bracing,ETABS.

\section{Introduction}

All structures should be designed to resist seismic and/or wind vibrations. The seismic regulations in countries at risk of earthquake are aimed to safeguard against major structural failures and loss of life but when it comes to comfort at high levels, the displacement of a structure is an important factor.[1-5]Khouri et. al. have shown that in order to guarantee comfortand safety at high levels, the drift should be limited to a value related to the capacity of the lateral load resisting elements at the point of maximum moment application, i.e. at the lowest point of the shear wall.[6-7]

To estimate the impact of an earthquake on a building, the main factors that specify the seismic response of the structure are the natural period and mode shapes. According to Housner and Brady, the displacement of a structure and the natural period of vibration are the most informative factors about the structural behavior of buildings.[8] In addition, mode shapes show the distribution of deformation within the structure; this allows the determination of the solicited forces and moments in the structure.[9]

In fact, seismic design of buildings is not only limited to the reinforcement of the supporting elements of the structure but also to the general movement. Displacement of structures is becoming increasingly important due to the fact that traditional low rise structures are being replaced by high rise slender towers. This is perhaps due to the lack of land that is causing such a revolution especially in cities.[9]

Thus, recent researchers and structural analysts are trying to find new ways to reduce the maximum displacement of structures. The traditional most commonly used method to reduce wind or seismic vibrations is the Tuned Mass Damper (TMD) or Pendulum Tuned Mass Damper (PTMD). This device isusually installed at the top of a structure and is coupled to its movement so that it oscillates out of phase with the structure to control and reduce the overall displacement.[10]

The TMD assembly presented in Figure 1 is considered to be a very effective method for reducing the displacement of a structure. However, the cost may be relatively high; for example, Taipai 101 PTMD direct cost was about 4 million dollars in 2003 and the maximum displacement reduction was about $30 \%$. This PTMD required, in addition to the complicated installations, a large and expensive sellable space; also, due to its large mass (730 Tons), the impact on the structural elements was large.[11]If the combination of a tuned mass, spring and damper can reduce the displacement of a structure, what will be the effect of springs implanted at different places in a structure?

The goal of this research is to find possible locations for these springs, their advantages and disadvantages as well as their impact on the reduction of the global displacement of a tower;it also determines the best locations for placing these springs. 


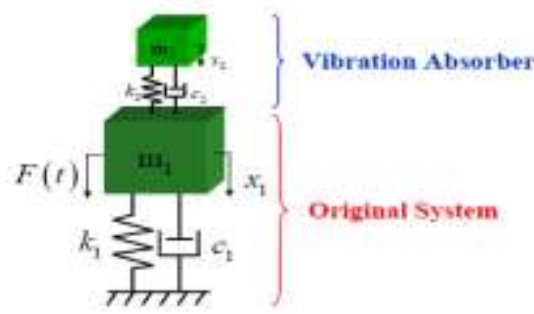

Figure 1: Typical Tuned Mass Damper.

\section{New Displacement Reduction Method}

The objective is to come up with a new displacement reduction technique using high stiffness springs by installing them at different predetermined locations in the structure. According to FIP industrial, an Italian company specialized in the production of springs and dampers, the maximum spring stiffness that they manufacture is $560 \mathrm{KN} / \mathrm{lm}$. The stiffness that was used in this study is limited to $500 \mathrm{KN} / \mathrm{lm}$.Modeling of the structure was performed using ETABS software. Springs were modeled by bar elements with elastic stiffness along the axis of the element equal to $500 \mathrm{KN} / \mathrm{lm}$. For the preliminary evaluation of the technique, many trials with springs placed at various sensitive locations in various types of structureswere studied; some of the spring configurations are presented in yellow in Figures 2.a, 2.b and 2.c.Regarding seismic loads, the spectrum presented in Figure 3 was used in the analysis.

\subsection{Installation of horizontal springs into the diaphragm of the roof slab}

In this method, openings were made in the diaphragm of the slab of the last story without any impact on the architecture of the building as presented in Figures 2.a and 2.b. The springs are concealed inside the slab; they stiffen the diaphragm and act as a brace to the vertical elements and to the entire structure in agreement with TENSACCIAI [12] who mentions that prestressed cables within the slab stiffen the panel and links the supporting elements together to reduce the displacement.

\subsection{Installation of horizontal springs connecting the outer columns of the last story}

Among the different methods tried, this method is the easiest to apply. The springs connect the vertical structural elements to form one assembly at the top as shown in Fig. 2.c. One drawback in this method is that the columns receive lateral forces that generate high shear stresses; these stresses have to be considered and designed for.

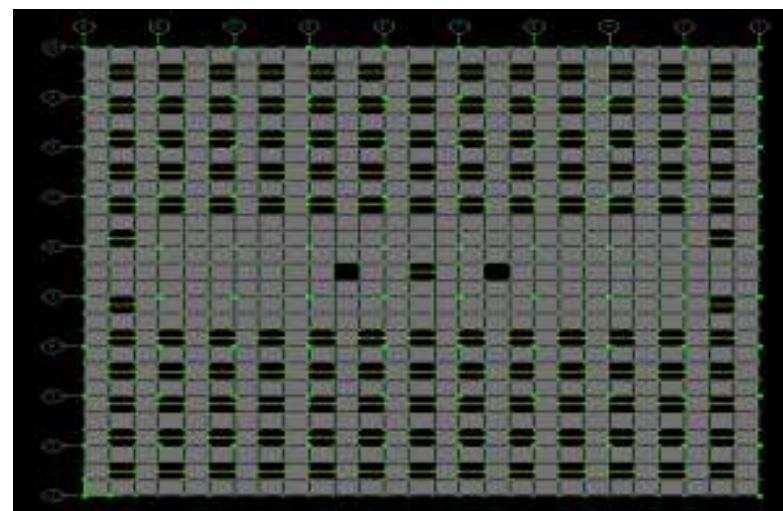

Figure 2.a. Installation ofsprings in linear patterns within the slab diaphragm.

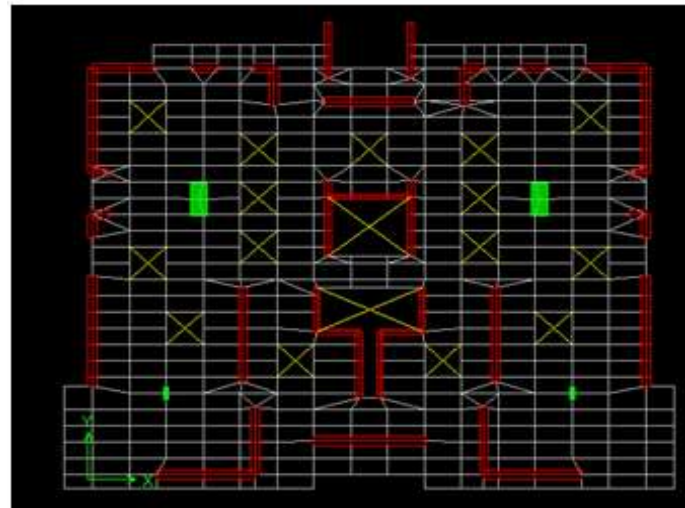

Figure 2.b. Installation of springs in cross patternswithin the slab diaphragm. 


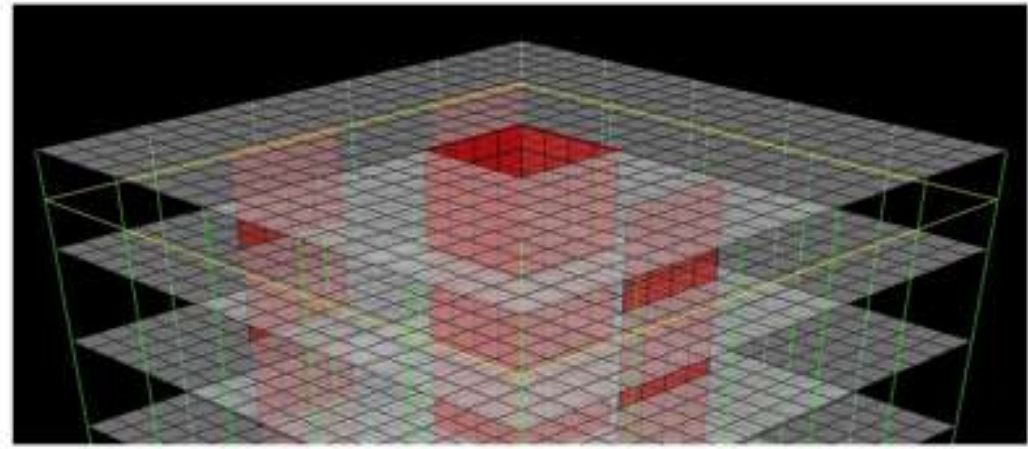

Figure 2.c. Installation of springs horizontally connecting the outer columns of the last story.

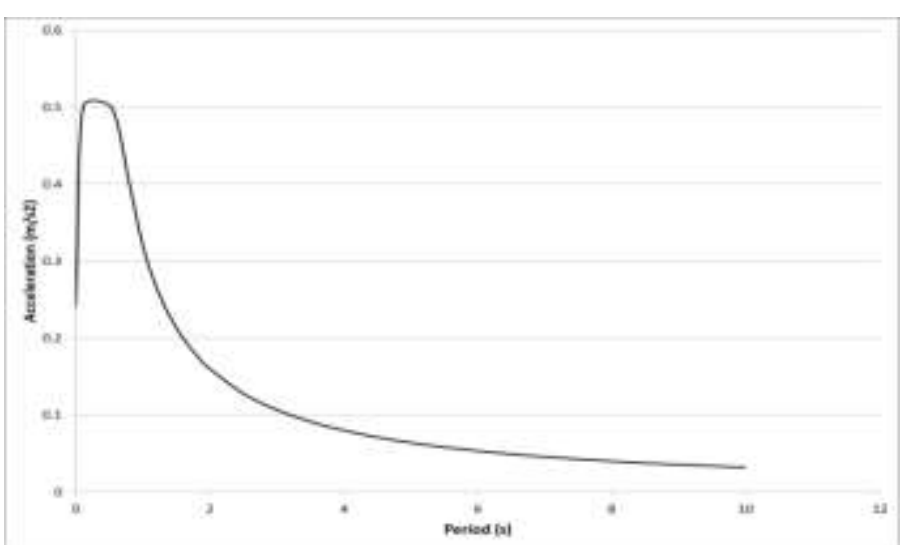

Figure 3: Spectrum used forthe seismic analysis.

Comparing the above procedures it is observed that they can be applied to any structure and the method of placing horizontal springs connecting the outer columns of the last story as presented in Figure 2.c. gave the largest displacement reduction ratio and is easier to apply than any other method tried. Given the above success with the utilization of springs, the question that remains is: At what story level would be the most effective positioning of these elastic members in the building? In the following, the variation of the displacement reduction ratio is studied depending on the location of the springs in the structure.

\section{Application of springs at different levels of the structure}

Since the configuration presented in Figure 2.c gave the highest displacement reduction ratio and it is relatively easy to apply, the analysis from now on in this article considers only this configuration. In order to reduce the variables and be consistent, a frame structure was considered with no shear walls. Also, preliminary design of the structure was performed where drop down loads for the columns was carried out for dimensioning the vertical members. For the seismic loads, the spectrum presented in Figure 3 was also used in the analysis.For a twenty story building, the springs are now installed in each floor separately and analyzed to determine the impact of the springs installed in each floor alone on the reduction of the overall displacement.

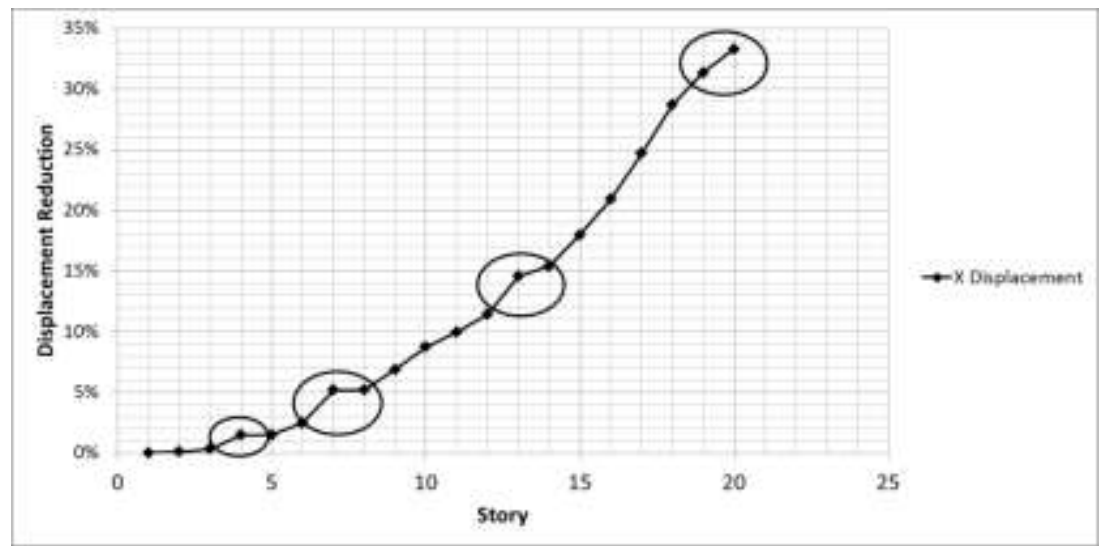

Figure 4: Variation of the reduction of the displacement as a function of the location of the springs installed horizontally between the outer columns in each floor alone. 
According to Figure 4, it can be observed that the reduction of the displacement is maximum when the springs are applied on the columns of the top floor of the structure. This reduction gradually decreases to zero as the position of the spring decreases towards the bottom of the building as expected. However, it can also be observed that in Figure 4, there are about four points of discontinuity in the graph; evaluating these points closely, it is noticed that they correspond to the inflection points of the first three modes of deformation presented in Figure 5. Consequently, it was concluded that the natural mode shapes have a great influence on the effectiveness of the spring positioning.

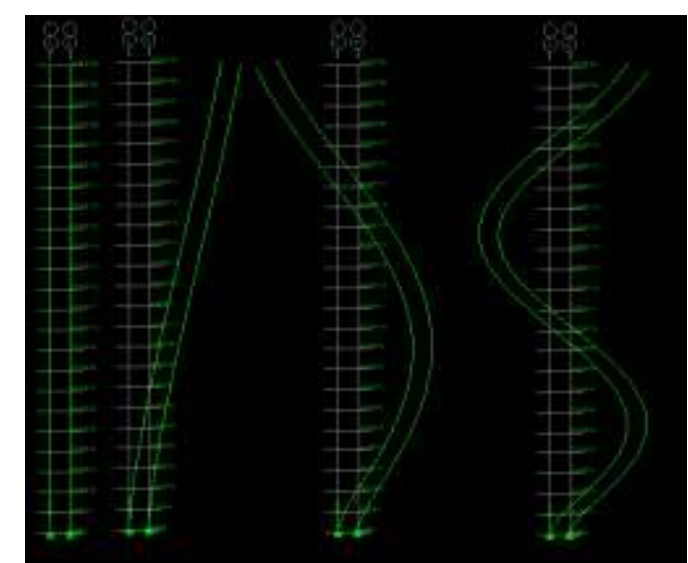

Figure 5: First Three Modes of Deformation for a typical Structure.

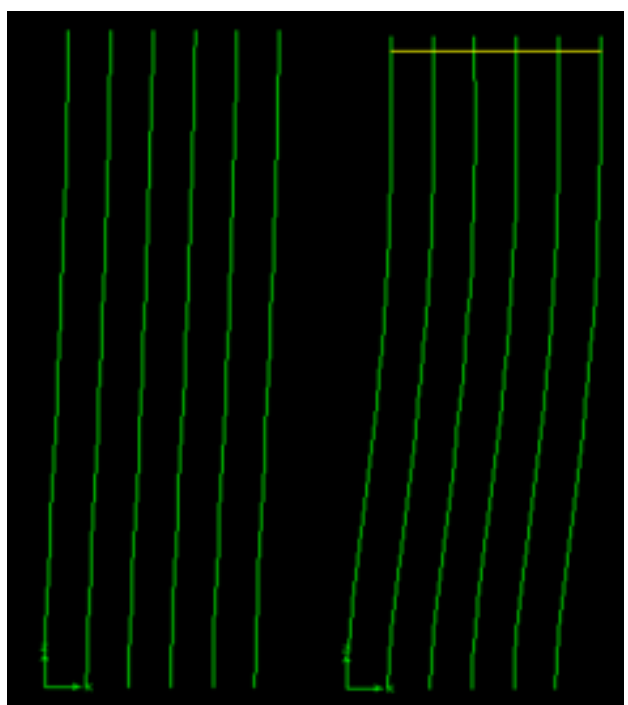

Figure 6: First Mode of Deformation for a typical structure without and withsprings installed at the top floor.

It is noted from Figure 6 that the springs installed at the summit of the building have changed the behavior of the structure. In fact, they have confined the bending of the tower towards its central axis; i.e. the tangent at the top of the deformed structure becomes nearly vertical in the presence of springs.It is therefore clear that springs placed at the top floor transform the shear deformation into a mixed deformation between shear and flexure, and consequently the lateral displacement is reduced.

\section{Springs and Mode shapes}

To investigate the behavior of the structure considering the mode shapes presented in Figure 7, springs were placed on the floors corresponding to the inflection points of the first three mode shapes. Four cases for the spring configuration connecting the outer columns of the identified floors were considered.

Case A: springs placed only on the top floor of the tower.

Case B: springsplaced to the inflection points of the second mode.

Case $C$ : springsplaced to the inflection points of the third mode.

Case D: Union of A, B and C.

This distribution of springs was studied for 10, 20, 30, 40 and 50 story buildings. 

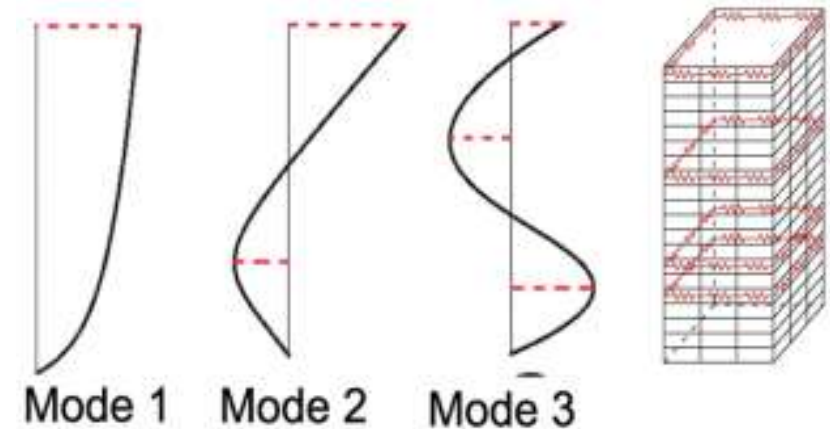

Figure 7: First three mode shapes with the schematic location of the springs.

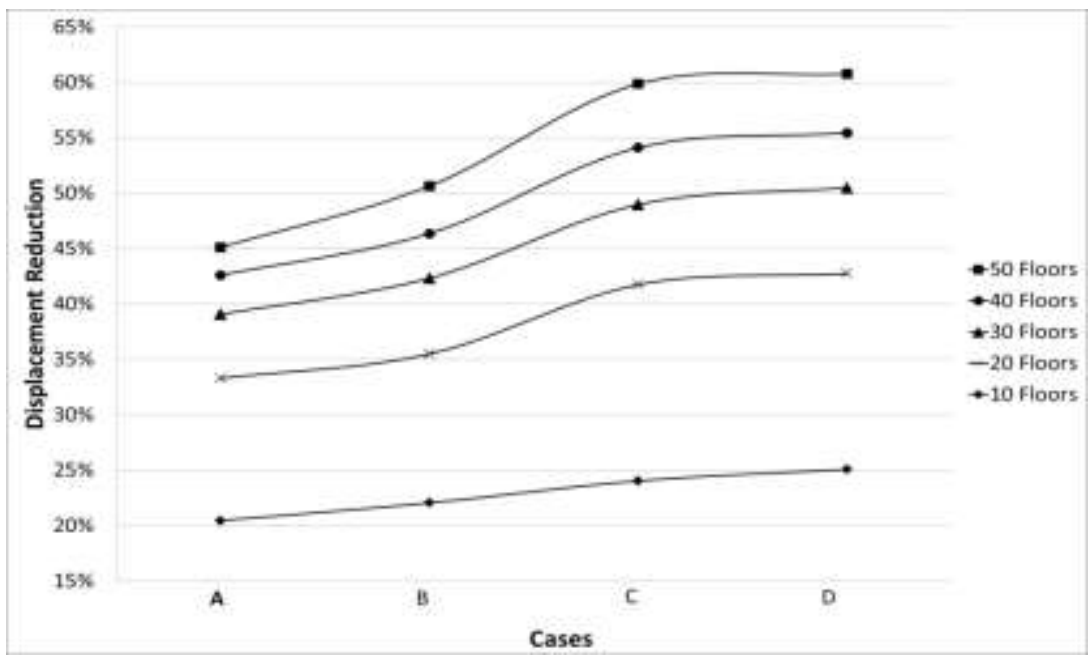

Figure 8: Reduction of displacement for the different cases when springsare placed horizontally between columns.

From the graph of the Figure 8, we note that the reduction of displacement increases with the number of floors studied. The efficiency of the method increases with the flexibility of the structure under consideration. This means that when the number of stories increase the structure is more flexible and the method is more efficient. This is presented in Figure 8 where the slope of the line connecting the result of case B and case C increases as the number of stories increase.

In order to check the effectiveness of the springs placed specifically at the floors corresponding to the inflection points of the first three modes, a model was constructed and analyzed with springs placed at random stories that do not correspond to the inflection points of the modes; the obtained results showed no significant displacement reduction.

It was concluded that the application of springs in floors coinciding with the inflection point of the mode shapes of the structure give a high reduction of displacement and will not have significant effect if applied at floors other than the ones corresponding to the inflection points of the first three modes.

TABLE 1: Displacement Reduction of a 50 stories buildingwithsprings installed at the top floor alone and with springs installed at the inflection points of the first three mode shapes.

\begin{tabular}{|l|l|l|l|}
\hline Case & Without Springs & $\begin{array}{l}\text { Displacement with Springs } \\
\text { on top Floor only }\end{array}$ & $\begin{array}{l}\text { Displacement with Springs on Inflection } \\
\text { Points of the First Three Modes }\end{array}$ \\
\hline Maximum Displacement (m) & 1.6282 & 0.8939 & 0.6154 \\
\hline Ratio & 1 & $0.451 \%$ & $0.620 \%$ \\
\hline
\end{tabular}

Table 1 shows a comparison between various configurations; without springs, with springs only at the top floorand with springs placed at the inflection points of the first three modes. Results show that placing the springs at the top floor alone can reduce the displacement by about $45 \%$, while placing the springs at locations corresponding to the inflection points of the first three modes can reduce the displacement by about $61 \%$. It is noted as well that the higher the rise of the structure the more the percentage reduction of the displacement. For all the buildings analyzed, Figure 8 shows that the curves have asymptotic form and appear to reach an upper reduction limit. 


\section{Conclusion}

Investigators, structural engineers and theoreticians have done significant amount of research in the hope of trying to find the best procedure to reduce lateral displacement in high rise buildings. All sorts and forms of TMDs and PTMDs have been previously investigated by others in terms of efficiency and cost effectiveness to reach a maximum displacement reduction of $30 \%$. In this study, a campaign was made on analyzing structures by placing springs at various locations hoping to find a method that can reduce the lateral displacement at a low cost. The work can be presented as follows:

1- High stiffness (500KN/Linear meter) springs were placed using various configuration to check the lateral displacement reduction. The most effective configuration was placing the springs connecting the outer columns of the last story of a structure; this is due to the fact that the installation of springs has transformed the shear deformation into a mixed deformation between shear and flexure.

2- Springs were placed in each floor alone and the structure was analyzed. This has identified discontinuities in the displacement reduction curves; these discontinuities turned out to correspond to the inflection points of the first three mode shapes.

3- Normal mode analysis was done on 10, 20, 30, 40 and 50 story buildings to determine the location of the inflection points of the first three modes for each structure.

4- With springs installed at the inflection points of the first three mode shapes, dynamic analysis was performed and the displacements were extracted at the summit of every building.

The findings can be summarized as follows:

1- For a 50 story building, high stiffness springs applied continuously connecting the outer columns of the structure at the floors corresponding to the inflection point of the first three modes can reduce the lateral displacement by about $60 \%$ as compared to a structure without any displacement reduction method. One disadvantage in this method is that large shear forces are generated in these columns and have to be accounted for in the design.

2- Method becomes more effective for high rise buildings; the more flexible and slender the structure is, the more the displacement reduction. However, this relationship depends on the continuity of the springs and their links. If there is a discontinuity in the springs, the displacement reduction significantly diminishes. So springs play the role of a bracing device connecting the vertical elements of a structure and chaining them.

3- Springs installed at the $1 / 3 \mathrm{H}, 2 / 3 \mathrm{H}$ and $\mathrm{H}$, where $\mathrm{H}$ is the total height of the structure have also proven to be very effective in the displacement reduction but not as effective as the springs installed at the inflection points of the first three modes.

Studying the economic impact of this method compared to traditional ones, it is noted that if the price of installed one linear meter of a $500 \mathrm{KN}$ spring is $\$$ US 2,500, then for a $180 \mathrm{~m}$ perimeter of the building, the total cost would be $\$$ US 450,000. Comparing this number to the Millions cost of the Taipei 101 tower PTMD in addition to the lost useful/sellable space and the additional expenses pertaining to the larger structural members, it is obvious that this new method costs much less; This is due to the fact that the installation process is much easier and the space used is insignificant compared to the space utilized by a PTMD.

Finally, this work can serve as a research starting point from which investigators in this field could start to implement these ideas in seismic codes considering various seismic parameters; this is in addition to various structural properties such as floor surface area, asymmetry in the structure and other factors in order to establish a relationship between the reduction of the displacement and the base parameters of this method. It would be interesting to see if the application of these springs can be used to reduce the asymmetry and consequently reduce the eccentricity and rotational forces in structures.

\section{Acknowledgement}

The author thanks Optimal Engineering Consulting and Contracting, (OECC) for sponsoring part of this work, and thanks to the Lebanese University, Faculty of Engineering, Branch II for sponsoring the other part of this on-going research.

\section{References}

[1]. Uniform Building Code, by international Conference of Building Officials, Whittier, California, 1997.

[2]. International Building Code, IBC-2012 Edition, Published by the International Code Council, INC., 2012.

[3]. Règle de Construction Parasismique, Règle PS applicables aux bâtiments - PS 92 Normes NF P 06-013, 1992.

[4]. Standards for Seismic Civil Engineering Construction in Japan, Earthquake Resistant Regulations for Building Structures in Japan, Tokyo, Japan, 2000.

[5]. Lebanese Code, General Seismic Design Guidelines and Regulations, Beirut, Lebanon, 1997.

[6]. Khouri, M. F., Drift Limitations in a Shear Wall Considering a Cracked Section,International Journal of Reliability and Safety of Engineering Systems and Structures, 1 (1), pp. 31-38, 2011.

[7]. Khouri, M. F. and Elias, W. J., On the General Evaluation of the Maximum Allowable Drift at the Top of Shear Walls (Constant and Variable Stiffness), International Journal of Civil Engineering and Construction Science, Vol. 1, (2), pp. 18-25, 2014. 
[8]. Housner, G. W. and Brady, A. G., Natural periods of vibration buildings, Journal of the Engineering Mechanics Division, 89:31-65, 1963.

[9]. Michel, C., Vulnérabilité Sismique de l'échelle du bâtiment à celle de la ville, Apport des techniques expérimentales in situ, Thèse UJF, Grenoble, France, 2007.

[10]. Abdulsalam, I., Al-Janabi, M. and Al-Taweel, M. G., Optimum design of tuned mass damper systems for seismic structures, ERES VII, Vol. 104, p.p. 175-184, WIT Press, UK, 2009

[11]. Poon, D., Shieh, S.S., Joseph, L., and Chang, C.C., Structural Design of the Taipei 101, The Worls's Tallest Building, CTBUH Conference, Seoul, Korea, 2004.

[12]. TENSACCIAI, Guide to Post-Tensioning Systems for Slabs, Document DTS-004 Rev. 1, Technical Department, Milano, Italy, 2008 .

Prof. Michel F. Khouri received his Ph.D. from The University of Michigan, Ann Arbor, in 1989. Since 1993, he is a professor of Civil Engineering at the Lebanese University, Faculty of Engineering, Branch II. Since February 2015, he has been serving as the Director of the faculty of Engineering; he has also served as the Chairman of the Civil Engineering Department, on and off, for fourteen years between 1997 and 2015. He has written many articles in the area of Finite Element Analysis, Structural Dynamics and Shell Analysis.

Eng. Elias Bechara El Haber, received his M2R from The Lebanese University, "Ecole Doctoral des Sciences et de Technologie" and "Université de Lille1", France. He is currently working on his PhD in the area of seismology. 